ACCEPTED MANUSCRIPT

\title{
Experimental and theoretical study of Co sorption in clay montmorillonites.
}

To cite this article before publication: Arles Gil Rebaza et al 2018 Mater. Res. Express in press https://doi.org/10.1088/2053-1591/aab4dd

\section{Manuscript version: Accepted Manuscript}

Accepted Manuscript is "the version of the article accepted for publication including all changes made as a result of the peer review process, and which may also include the addition to the article by IOP Publishing of a header, an article ID, a cover sheet and/or an 'Accepted

Manuscript' watermark, but excluding any other editing, typesetting or other changes made by IOP Publishing and/or its licensors"

This Accepted Manuscript is @ 2018 IOP Publishing Ltd.

During the embargo period (the 12 month period from the publication of the Version of Record of this article), the Accepted Manuscript is fully protected by copyright and cannot be reused or reposted elsewhere.

As the Version of Record of this article is going to be / has been published on a subscription basis, this Accepted Manuscript is available for reuse under a CC BY-NC-ND 3.0 licence after the 12 month embargo period.

After the embargo period, everyone is permitted to use copy and redistribute this article for non-commercial purposes only, provided that they adhere to all the terms of the licence https://creativecommons.org/licences/by-nc-nd/3.0

Although reasonable endeavours have been taken to obtain all necessary permissions from third parties to include their copyrighted content within this article, their full citation and copyright line may not be present in this Accepted Manuscript version. Before using any content from this article, please refer to the Version of Record on IOPscience once published for full citation and copyright details, as permissions will likely be required. All third party content is fully copyright protected, unless specifically stated otherwise in the figure caption in the Version of Record.

View the article online for updates and enhancements. 


\begin{abstract}
Montmorillonite (MMT) clays are 2:1 layered structures which in natural state may allocate different hydrated cations such as $\mathrm{M}-\mathrm{nH}_{2} \mathrm{O}(\mathrm{M}=\mathrm{Na}, \mathrm{Ca}, \mathrm{Fe}$, etc. $)$ in its interlayer space. Depending on the capability for ion sorption, these materials are interesting for environmental remediation. In this work we experimentally study the Co sorption in a natural Na-MMT using UV-visible spectrometry and XRD on semi-oriented samples, and then analyze the sorption ability of this clay by means of $a b$ initio calculation performed on pristine MMT. The structural properties of Na-MMT and Co-adsorbed MMT, and the hyperfine parameters at different atomic sites were analyzed and compared with the experimental ones for the first, and for the case of the hyperfine parameters, presented for the first time for the last. The theoretical predictions based on total energy considerations confirm that $\mathrm{Co}$ incorporation replacing $\mathrm{Na}$ is energetically favorable. Also, the basal spacing $\mathrm{d}_{001}$ experimentally obtained is well reproduced.
\end{abstract}

\title{
1- Introduction
}

From the beginning of the industrial revolution, environmental pollution by heavy metals appeared as a direct consequence, and its reversal represents a challenge for modern life. In this scenario pollutants generation and the deposition controls constitute a very important topic due to the negative effects that these elements could cause both on the human health and the environmental quality. Among the mechanisms used for heavy metal removal from effluents, ion exchange allows the use of low cost and environmental friendly materials, like clay minerals and its derivatives (modified clays that enhance the sorption process of the sorbent material) ${ }^{1-}$ 3. Among them, Montmorillonite (MMT), a 2:1 clay mineral, is one of the most promising candidates for decontamination and disposal of wastewater with high-level heavy metal cation content, due to its relatively high specific area and cation exchange capacity ${ }^{4,5}$. Cobalt is one of the toxic metals affecting the environment. It is widely present in effluents and is originate from different human activities ${ }^{6}$. Its origin is connected with urban storm-water runoff coming from electronic, electroplating, paints and pigments, 
mining, metallurgical and nuclear industries (principally from wastes released from pressurized water nuclear power reactors and from medical applications $)^{6-10}$. Because it can affect human health and the environment its removal from effluents is essential ${ }^{6}$ 11 .

Some studies were performed testing the efficiency of Co sorption in natural and modified $\mathrm{MMT}^{4,12-24}$. The results indicated that the MMT systems can sorb and retain Co depending on the system itself and the physical and chemical conditions. Although the main expected sorption mechanisms in clays are cationic exchange and surface complexation, sorption mechanisms of Co in MMT are still not clear.

Between the experimental techniques used to enlighten the mechanisms involved in metal/clay complexation, Nuclear Magnetic Resonance (NMR) became an important tool due to its high sensitivity to the local environment of the atoms and the chemical bonds. Clay layers were previously studied with this technique using ${ }^{25} \mathrm{Mg}$, ${ }^{27} \mathrm{Al}$ and ${ }^{29} \mathrm{Si}$ as probe atoms ${ }^{25-32}$, whereas for the clay interlayer and swelling behavior, the studies were performed using ${ }^{113} \mathrm{Cd},{ }^{133} \mathrm{Cs}$, and ${ }^{23} \mathrm{Na}$ probes ${ }^{33-37}$.

Computational quantum simulations have proven to be a suitable tool for understanding the microscopic processes that conduct to the physical and chemical properties of materials. Beyond the simplifications that are made in comparison to the complexity of real materials, they can lead to a better understanding of individual processes involved. Recently ab-initio calculations within the Density Functional Theory (DFT) were used to investigate the mechanisms involved in metal sorption on clays ${ }^{38-42}$ and especially in $\mathrm{MMT}^{43-51}$. Within this theory some well-tested codes have implemented the determination of the hyperfine parameters ${ }^{52-53}$. In the present work a combined DFT and experimental study for Co sorption in MMT is reported. The calculations are discussed in term of the energetic and structural features accompanying the $\mathrm{Na}$ to $\mathrm{Co}$ interlayer exchange in pristine MMT. The electronic properties of MMT and Co sorbed MMT are also analyzed.

The paper is organized as follows: in Section 2 a brief description of the system is given. In Section 3, the experimental methods and the results for the determination of the $\mathrm{CO}^{2+}$ sorption are presented. Section 4 describes the models and computational details of the ab-initio calculation. In Section 5 the results of the calculations are shown. This section is divided in three subsections: a- the results concerning the energy formation and cell elongation, b- the predicted hyperfine characterization, and c- the comparison with experimental data obtained from literature. Finally, Section 6 is reserved to the conclusions. 


\section{2- The system under study.}

The MMT structure could be described as a 2:1 phyllosilicate constituted by a laminar structure with an elongated cell along the $c$ axis having a triclinic unit cell with space group $\mathrm{P} 1$. The layers consist of an octahedral sheet linked with two tetrahedral sheets sharing apical oxygen atoms. The $\left((\mathrm{Al} / \mathrm{Mg}) \mathrm{O}_{6}\right)$ units form the octahedron layer sandwiched by two layers of $\left(\mathrm{SiO}_{4}\right)$ tetrahedrons. In the interlayer region different cations can be allocated, such as $\mathrm{Na}$ and $\mathrm{Co}$, with different hydration degrees. The interactions between layers are supposed to be weak. Pristine Na-MMT have as chemical formula $\mathrm{Na}\left[\left(\mathrm{MgAl}_{3} \mathrm{O}_{8}(\mathrm{OH})_{4}\left(\mathrm{Si}_{8} \mathrm{O}_{12}\right)\right]_{2}+\mathrm{m}\left(\mathrm{H}_{2} \mathrm{O}\right)\right.$. Co-sorbed MMT structure, labeled as Co-MMT, was generated by replacing the $\mathrm{Na}^{+}$with $\mathrm{Co}^{2+}$ ions linked with the corresponding $\mathrm{H}_{2} \mathrm{O}$ molecules, as will be detailed in the next sections. In Figure 1 it can be seen the starting structure before internal atomic position relaxation for the case $\mathrm{m}=$ 4 with one $\mathrm{Na}$ per unit cell. A second $\left(\mathrm{Na}+4 \mathrm{H}_{2} \mathrm{O}\right)$ unit and some $\left((\mathrm{Al} / \mathrm{Mg}) \mathrm{O}_{6}\right)$ units in the neighbor unit cell in the a axis direction are depicted for clarity.

\section{3- Experimental}

The $\mathrm{Co}^{2+}$ sorption experiments were performed using a natural Na-MMT from Río Negro State, Argentina. The sorption studies were performed in batch conditions $\left(\mathrm{V}=25 \mathrm{ml}\right.$ ), using a $\mathrm{Co}^{2+}$ initial concentration of $100 \mathrm{mg} / \mathrm{l}$ (obtained after dissolving the corresponding masses of $\mathrm{CoCl} .6 \mathrm{H}_{2} \mathrm{O}$, provided by Sigma Co.), a solid/liquid ratio of 1 $\mathrm{g} / \mathrm{l}, \mathrm{pH}=6$ and a contact time of $24 \mathrm{~h}$. Sorption experiments were performed in duplicate.

After the sorption experiment, the liquid and solid phases were separated by centrifugation. The solid phase was dried at $60^{\circ} \mathrm{C}$ and stored in a desiccator for its posterior characterization. The remaining $\mathrm{Co}^{2+}$ concentration in the liquid phase was determined and from this value the sorbed $\mathrm{Co}^{2+}$ was obtained. $\mathrm{Co}^{2+}$ determination was performed using a UV-visible spectrometer, following the methodology proposed by Sandell ${ }^{54}$.

The structure changes of the solid phase after the Co-sorption experiments were determined by XRD technique. Partial X-ray diffraction patterns of semi-oriented clays were collected using a Philips 3020 equipment, operating to $35 \mathrm{~mA}$ and $40 \mathrm{kV}$, with $\mathrm{Cu} \mathrm{Ka}$ radiation, from $2^{\circ}$ to $10^{\circ}$ (2 theta), with $0.02^{\circ}$ stepping angle and $10 \mathrm{~s} / \mathrm{step}$.

The results of the $\mathrm{Co}^{2+}$ sorption experiments confirm that $\mathrm{Co}^{2+}$ ions were sorbed into the samples. The sorption percentage for this cation resulted as high as $80 \pm 2 \%$. Before and after the sorption process, XRD analyses were carried out for oriented 
samples in order to determine the $\mathrm{d}_{001}$ parameter (Figure 2). The obtained results also indicate that after sorption experiments Co incorporation in the interlayer was produced, due to an expansion in the c-axis direction. For the determination of the $d_{001}$ distance, Voight functions were fitted to the XRD spectra. In the case of the sample before the $\mathrm{Co}^{2+}$ sorption procedures, two Voight functions were used to take into account the high asymmetry of the corresponding peak. The determined $d_{001}$ distance for Co-MMT was $15.71 \pm 0.06 \AA$ while the corresponding for the natural Na-MMT was $12.58 \pm 0.04 \AA$ and $13.55 \pm 0.07 \AA$, resulting in a high enlargement of the interlayer spacing.

\section{Modeling and computational details}

Natural samples of MMT may have different low concentrations of impurities (such as Fe, Ca), and also cation exchange between $\mathrm{Si}, \mathrm{Al}$ and $\mathrm{Mg}$. The effect of such defects in macroscopic structures is out of the scope of this study. The starting atomic positions for the ab-initio calculations for the Na-MMT and Co-MMT in combination with the different hydration states were taken from the work of Pirillo et al. ${ }^{46}$ with lattice parameters $a=5.2584 \AA b=8.7669 \AA \mathrm{c}=12.8511 \AA$ and $\beta=95.3443$. Co-MMT structure was generated by replacing the $\mathrm{Na}$ with $\mathrm{Co}$ atoms. For the initial $\mathrm{m}-\mathrm{H}_{2} \mathrm{O}$ units atomic positions we considered starting from symmetric distributions with the $\mathrm{H}$ pointing outward the corresponding cation as can be seen in Fig. 1.

Following the ideas of Berghout et al ${ }^{45}$ and the studied performed by Pirillo et al. ${ }^{46}$ for the simulated Na-MMT, we considered three different $\mathrm{Na}$ concentration/hydration states: a- One $\mathrm{Na}^{+}$atom surrounded by four $\mathrm{H}_{2} \mathrm{O}$ in the unit cell (NaM1); $b$ - Two $\mathrm{Na}^{+}$atoms, each one of them surrounded by two $\mathrm{H}_{2} \mathrm{O}(\mathrm{NaM} 2)$; and $c$ Two $\mathrm{Na}^{+}$atoms, each one of them surrounded by four $\mathrm{H}_{2} \mathrm{O}(\mathrm{NaM} 3)$. For the simulated Co-MMT we considered the case of two $\mathrm{Co}^{2+}$ atoms, each one surrounded by $\mathrm{six}_{2} \mathrm{O}$ in the unit cell (CoM1). For each one of the models, refined atomic positions and lattice constants were obtained as explained below.

All the simulations of the electronic structure were performed within DFT. So, as starting step the density functional first-principles simulations were performed based on the numerical Linear Combination of Atomic Orbitals (LCAO) method as implemented in the Siesta Code $^{53}$. The calculations have been carried out within the Generalized Gradient Approximation (GGA), using the functional parametrized by Perdew, Burke and Ernzerhof (PBE) to simulate the electronic exchange and correlation potentials ${ }^{55}$. All the core electrons were replaced by ab-initio norm-conserving pseudopotentials 


\section{Results and Discussion}

\section{a- Formation energy and cell elongation.}

The calculated lattice parameters and $d_{001}$ values after optimization of the initial parameters of the different cell considered are listed in Table I. From this table and Fig. 2 it can be seen that the experimental and theoretically predicted $d_{001}$ for the Co-MMT are in good agreement. The lattice was strongly expanded in the $c$ direction after the procedure from an initial value of $c=12.851 \AA$ to the final $c=15.842 \AA$ were all the internal forces and the cell stress are nearly zero. With the final lattice constants, the resulting $d_{001}$ resulted $15.81 \AA$, which should be compared with the experimentally obtained $d_{001 \text { exp-Co }}=15.5 \pm 0.6 \AA$. Regarding the Na-MMT structures, the resulting $d_{001}$ obtained values are: for $\mathrm{NaM} 1 \mathrm{~d}_{001 \mathrm{NaM} 1}=12.89 \AA$; for $\mathrm{NaM} 2 \mathrm{~d}_{001 \mathrm{NaM} 2}=12.74 \AA$; and for $\mathrm{NaM} 3 \mathrm{~d}_{001 \mathrm{NaM} 3}=14.19 \AA$. These results can help to distinguish which model is closer to the experimental sample. The $d_{001}$ for the case of two Na atoms with $8 \mathrm{H}_{2} \mathrm{O}\left(4 \mathrm{H}_{2} \mathrm{O}\right.$ for each $\mathrm{Na}$ ) $\mathrm{NaM} 3$ is much higher than those obtained in this work $12.58 \pm 0.4 \AA$ and 
$13.55 \pm 0.07 \AA$. So, NaM3 does not reproduce well the sample before the $\mathrm{Co}^{2+}$ sorption. Regarding the models that take into account 4 molecules of $\mathrm{H}_{2} \mathrm{O}, \mathrm{NaM} 1$ and $\mathrm{NaM} 2$, on the basis of the $d_{001}$ it is not easy to reveal the more appropriate model. Both structures give $d_{001}$ values close to one of the experimentally obtained $12.58 \pm 0.4 \AA$, thus describing well enough part of the Na-MMT sample, but strictly comparing the obtained numbers, together with the obtained lattice parameters, the NaM2 is closer. It must be mentioned that in real samples coexistence of different hydration states can occur. This effect have been observed and discussed in previous works ${ }^{63}$. As it was mentioned, in our samples two Voight functions were needed to take into account the asymmetry of the XRD peak. The site with $d_{001}=13.55 \pm 0.07 \AA$ was not well reproduced for any of these models.

On the other hand, the comparison of the predicted Na-MMT and Co-MMT $d_{001}$ shows that the Cobalt incorporation in the MMT lattice produces an expansion of the $\mathrm{d}_{001}$ plane, shifting the $\mathrm{d}_{001}$ about $3.23 \AA$, close to that determined experimentally. So, from this correspondence it can be inferred that Co sorption in MMT incorporates the Co atom in the interlayer of the MMT clay, and not as a superficial adsorption, being this fact up to now not discarded.

In order to quantitatively evaluate if the Co sorption is favored, total energies obtained from ab-initio calculation for MMT system with $\mathrm{Na}$ and Co performing using the GIPAW code with and without spin polarization were performed. For the case of Co-MMT, the spin-polarized case was that with lower energy, so all the energy differences are calculated referred to the spin-polarized case. We considered the formation energy and the bond energy as:

$$
\begin{aligned}
& \Delta E_{X-M M T}^{\text {form }}=E_{\text {tal }}-\left(E_{\text {layer }}+2 E_{X}+n E_{\mathrm{H}_{2} \mathrm{O}}\right) \\
& \Delta E_{X-M M T}^{\text {bond }}=E_{\text {total }}-\left(E_{\text {layer }}+E_{\text {interlayer }}\right)
\end{aligned}
$$

Where $X$ stands for $\mathrm{Na}$ or Co. For the calculation of the total energy $E_{X}$, there were computed the corresponding to the bulk compounds, divided by the number of atoms of the structure. For the $E_{\mathrm{H}_{2} \mathrm{O}}$ term, the total energy of the free molecule was calculated, and $\mathrm{n}$ represents de number of molecules for each case. For the $E_{\text {layer }}$ term, it was computed the total energy of the crystalline structure but without the atoms of the interlayer (Figure 3), and vice versa for the $E_{\text {interlayer }}$ term. In MMT the layers are negatively charged, so the presence of the cation in the interlayer stabilizes the structure. Then, the $E^{\text {bond }}$ can give information of the charge stability. The resulting energies using Eqs. (1) and (2) are shown in Table II. It can be seen that the Co 
incorporation related to the formation of the Co-MMT phase is favored with respect to the $\mathrm{Na}$ incorporation in the Na-MMT system, and the energy related with the charge stability remains the same. So, it can be concluded that Co-Na exchange is energetically favored.

\section{b- Hyperfine characterization}

As it is known the external magnetic field used in NMR experiments at probe sites are normally shielded by a shielding coefficient which depends on the local environment $\left(\sigma_{\text {sample }}\right)$. The determined experimental chemical shift is related with the isotropic shielding $\sigma_{\text {sample }}$ and could be compared with calculated ones taking into account the standard expression:

$$
\delta_{\text {chem }}=\sigma_{\text {Ref }}-\sigma_{\text {sample }}
$$

Starting from the optimized cell parameter, the NMR parameters were evaluated on each atomic site using the GIPAW code. The obtained magnetic shielding, the mayor component of the electric field gradient tensor represented in the local principal axis $V_{z z}$ and the corresponding asymmetry parameter $\eta=\frac{V_{x x}-V_{y y}}{V_{z z}}$ are summarized in Table III. Regarding the $\mathrm{O}$ atoms, it can be seen in Fig. 1 that the $\mathrm{SiO}_{4}$ tetrahedra are oriented in such a way that each tetrahedron has one basal plane approximately parallel to the interlayer, so, these are the oxygen atoms capable to bond with the $\mathrm{Na} / \mathrm{Co}+\mathrm{nH}_{2} \mathrm{O}$ units, although just one or two of them will effectively act as bonding atom. On the other hand, on the opposite vertex of the tetrahedron the corresponding $\mathrm{O}$ atom is shared with a $\left(\mathrm{Al} / \mathrm{MgO}_{6}\right)$ octahedron, thus acting as a bridge between these units. Moreover, the $\mathrm{O}$ atoms of the $\left(\mathrm{Al} / \mathrm{MgO}_{6}\right)$ units that are not shared with any $\mathrm{SiO}_{4}$ units form $(\mathrm{OH})^{-}$groups. Finally, there are $\mathrm{O}$ atoms that belong to the $\mathrm{H}_{2} \mathrm{O}$ units, and only bind with the $\mathrm{H}$ and the $\mathrm{Na} / \mathrm{Co}$. In Table III it can be seen that $\mathrm{O}$ atoms were correspondingly divided in three groups, named $\mathrm{O}_{\text {basal, }}, \mathrm{O}_{\text {apical }}$ and $\mathrm{O}_{\mathrm{OH}}$, corresponding to the first three groups respectively. The results for the last group are not shown. As it is known, the hyperfine parameters (HP) are highly sensitive to local distortions due to their dependence on the charge density near and at the nuclei positions. So, in perfect symmetric tetrahedron or octahedron units it should be expected similar values in the HP of the constituent $O$ atoms, and on the contrary, differences in the HP are signals of strong local deformations of the units. For example, in Table III it can be seen that, for the NaM1 structure, the $V_{z z}$ of the $\mathrm{O}_{\text {basal }}$ are mainly in 
the $9-10 * 10^{21} \mathrm{~V} / \mathrm{m}^{2}$ range, except for $01, \mathrm{O} 4$ and 011 . In Figure $4 \mathrm{a}$ it can be seen in correspondence that $\mathrm{O} 1$ form the chemical bond with the $\mathrm{Na}+4 \mathrm{H}_{2} \mathrm{O}$ unit, resulting the corresponding tetrahedron strongly deformed. In the upper part of the interlayer, $\mathrm{O} 4$ displaces from the basal plane towards the interlayer in a sort of $\mathrm{O}-\mathrm{H}-\mathrm{O}$ bridge, thus also producing a strong deformation of the tetrahedron. Finally, $\mathrm{O} 11$ is shared between the basal plane of the corresponding tetrahedron and a free $\mathrm{H}$. In correspondence, the

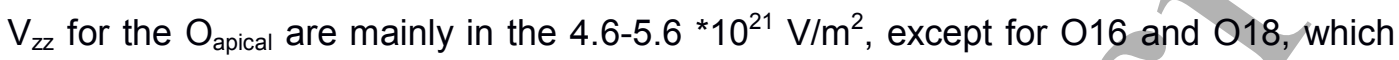
are the apical oxygen atoms of the deformed $\mathrm{SiO}_{4}$ tetrahedra that share the basal $\mathrm{O} 4$. A similar reasoning can be done for the HP parameters at the Si atoms in these structures: the $\mathrm{SiO}_{4}$ tetrahedrons of $\mathrm{Si} 3$ and $\mathrm{Si} 5$ are geometrically similar, as those of Si4 and Si6, then the corresponding $V_{\underline{z z}}$ and $\eta$ values are near the same. In the lower plane of tetrahedra in Fig. $4 a$ it can be seen that they are all geometrically different due to proximity of the $\left(\mathrm{Na}+4 \mathrm{H}_{2} \mathrm{O}\right)$ unit and the different bonding, consequently the HP of the corresponding Si atoms spread over a range of values. Interestingly, it should be noted that $V_{z z}$ and $\eta$ have much more sensitivity to the mentioned deformations than the $\sigma_{\text {sample }}$ for the case of $\mathrm{Si}$, and the opposite occurs for the O. For the case of the Al and $\mathrm{Mg}$ atoms, it should be noted that $\sigma_{\text {sample }}$ has nearly constant values around 545 ppm for both type of atoms, whereas the corresponding $V_{z z}$ and $\eta$ have very different values between atoms in same the group.

In the case of the oxygen atoms in the $\mathrm{O}_{\text {basal }}$ group of the $\mathrm{NaM} 2, \mathrm{O} 1, \mathrm{O} 3$ and $\mathrm{O} 4$ are the atoms that show out of range values. In Fig. $4 \mathrm{~b}$ it can be seen that $\mathrm{O} 1$ and $\mathrm{O} 3$ are the bonding atoms between the $\left(\mathrm{SiO}_{4}\right)$ layer and the $\left(\mathrm{Na}+2 \mathrm{H}_{2} \mathrm{O}\right)$ units, thus producing an elongation in the tetrahedral faces. $\mathrm{O} 4$ stands for an $\mathrm{O}-\mathrm{H}-\mathrm{O}$ bridge as in the previous case. In this case the similar deformed tetrahedra are those containing Si1 and Si7, and the pair Si2-Si8. Thus the corresponding apical oxygen 019-O13 and O20-O14 have very similar HP. Other pairs of similar $\mathrm{O}_{\text {apical }}$ bonding can be observed from Table $V$.

In Fig. 5 it can be observed the relaxed cell of the CoM1. As a difference with the NaM1 and NaM2 cases, it can be observed that the elongation of the cell in the cdirection causes the interlayer $\left(\mathrm{Co}+6 \mathrm{H}_{2} \mathrm{O}\right)$ units to be displaced further away from the $\mathrm{O}_{\text {basal }}$ atoms than in the previous cases, i.e., the enlargement is practically all contained in the interlayer spacing. As a result, in this structure do not appear $\mathrm{Co}-\mathrm{O}_{\text {basal }}$ chemical bonds similar to the $\mathrm{Na}-\mathrm{O} 1$ in the NaM1 or the $\mathrm{Na}-\mathrm{O} 1+\mathrm{Na}-\mathrm{O} 3$ of the NaM2. Nevertheless, $\mathrm{O} 4$ and $\mathrm{O} 3$ are displaced towards the interlayer, thus producing strongly deformed tetrahedra. This fact is reflected in their corresponding HPs which are out of the mean values also for $\mathrm{V}_{\mathrm{zz}}$ and $\sigma_{\text {sample }}$ (Table III). Regarding the $\left(\mathrm{Co}+6 \mathrm{H}_{2} \mathrm{O}\right)$ units, it appears an unexpected behavior after relaxing the atomic positions. It can be observed 
that the corresponding units to $\mathrm{Co} 1$ and $\mathrm{Co} 2$ are different. Co1 maintains a nearly regular octahedron of $6 \mathrm{H}_{2} \mathrm{O}$ molecules, but $\mathrm{Co} 2$ is located in such a way that it is closer to one of the water molecules originally from Co1 (W1 in Fig. 5) than to one water molecule from its original unit (W2). So, this forms a strongly deformed octahedron, linked to the corresponding Co1 with a Co1-O-Co2 bridged structure, and releasing a water molecule.

\section{c- Comparison with experimental results}

From the ab-initio results the chemical shift for each probe site of the MMT can be determined. On one hand, for the use of Eq. 3 the corresponding $\sigma_{\text {Ref }}$ values must be provided, nevertheless a search in the literature does not shield unique values. On the other hand, other authors use an empirical model in which there is linear relation between the chemical shift $\delta_{\text {chem }}$ and the isotropic shielding $\sigma_{\text {sample }}$ in which the coefficients for the linearization are obtained from a linear regression from measurements on many different compounds:

$$
\delta_{\text {chem }}(p p m)=A * \sigma_{\text {sample }}+B
$$

Also for this approach, after a selected search within this model at least two pair of values can be found for the linear coefficients A and B. In Table IV there are shown the data collected from the literature.

Unfortunately, up to our knowledge there are no reports for measurements using the ${ }^{17} \mathrm{O}$ isotope as probe atoms for this type of MMTs, nor NMR experiments reported on Co-MMT. Thus, for the comparison with the experiment we will restrict to the HP on Al, Mg, Si and $\mathrm{Na}$ for the NaM1 and NaM2 structures. In Table V there are shown the HP obtained from the literature from NMR experiments on Na-MMT. From the predicted HP (Table III) we calculated the chemical shift for each one of these atoms, using Eq. 3 and Eq. 4. Thus we obtained a set of values that depend on the model and the experimental $\sigma_{\text {Ref }}$, and the $A$ and $B$ set of parameters. For $\sigma_{\text {sample }}$ for the different $\mathrm{Al}, \mathrm{Si}, \mathrm{Na}$ and $\mathrm{Mg}$ atoms we used those obtained from the corresponding average of the predicted values from Table III. For the determination of $V_{z z}$ form NMR data we used:

$$
\begin{aligned}
& C_{Q}=\frac{V_{z z} Q e}{h} \\
& P_{Q}=C_{Q} \sqrt{1+\frac{\eta^{2}}{3}}
\end{aligned}
$$


by means of the corresponding quadrupolar moment $Q$ after averaging the obtained moduli of the $\mathrm{V}_{z z}$ for the same type atoms.

As it can be seen, the calculated ${ }^{29} \mathrm{Si}$ chemical shift is in good agreement with the reported chemical shift in the literature. Regarding ${ }^{23} \mathrm{Na}$, the comparison of the calculated $\delta_{\text {chem }}$ with the experimental one becomes difficult due to the strong dependence on the A and B empirical parameters selection. Specially, the B parameter presents strong differences between the data form Ref[64] and Ref[37], and this difference particularly affects the results for chemical shifts near zero, as in this case. On the other hand, the $V_{z z}$ obtained values are not far from the experimental data. For $\mathrm{Mg}$, the calculated $\delta_{\text {chem }}$ using Ref[37] resulted higher than that observed in Ref[26]. Also, the $V_{z z}$ are higher for both models NaM1 and NaM2. On the contrary, the obtained $\eta$ are in good agreement with the experiment. For ${ }^{27} \mathrm{Al}$ it can be seen that $\mathrm{V}_{z z}$ are in good agreement with the range extracted from the work of Takahashi et al. (the range comes from the indetermination $\eta$, taking the extreme values 0 and 1) for both NaM1 and NaM2. Nevertheless it must be observed that the comparison is performed with the mean value of the $\mathrm{V}_{\mathrm{zz}}$ module for all the Al sites. While for NaM2 all the Al sites have uniform $V_{z z}$ values, the corresponding values in NaM1 present strong fluctuations. These fluctuations are not reflected in the individual $\sigma_{\text {sample, }}$ nonetheless the obtained chemical shifts resulted above the experimental result using Eq. 3 or Eq. 4.

\section{6- Conclusions}

Cobalt sorption on natural Na-MMT was experimentally studied. From the results of the XRD spectra and analysis of the solid and residual liquid phase it was concluded that $\mathrm{Co}^{2+}$ was introduced in the sample and as a result the layered structure was strongly enlarged in the direction perpendicular to the interlayer.

DFT calculations can be an important tool to contribute to resolve issues relating to the structure of natural and synthetic layered materials. This theory was successfully used to reproduce the changes introduced in MMT structure upon substitution of $\mathrm{Na}$ by $\mathrm{Co}$ as it was observed. Regarding the total energy values, $a b$ initio calculation predicts that the replacement, though sorption, of $\mathrm{Na}$ by $\mathrm{Co}$ in $\mathrm{Na}$ MMT is energetically favorable. Three different models with different hydration/Naconcertation state were tested to reproduce the Na-MMT samples and one for the obtained Co-MMT. Within these models of Na-MMT, two of them with $4 \mathrm{H}_{2} \mathrm{O}$ and one or two $\mathrm{Na}$ atoms give $\mathrm{d}_{001}$ parameters compatible with the natural sample, whereas the third model with $2 \mathrm{Na}$ atoms and $8 \mathrm{H}_{2} \mathrm{O}$ have been discarded due to the high $\mathrm{d}_{001}$ 
values obtained at equilibrium. The Co-MMT model with 2 Co atoms and $6 \mathrm{H}_{2} \mathrm{O}$ resulted in a $\mathrm{d}_{001}$ compatible with that obtained experimentally in this work.

In this work we observed that the substitution of the $\mathrm{Na}-\mathrm{n}(\mathrm{H} 2 \mathrm{O})$ by Co-m $(\mathrm{H} 2 \mathrm{O})$ produces not only an enlargement of the cell, but also a re-organization of some of the $\mathrm{O}$ atoms of the $\mathrm{SiO}_{4}$ tetrahedrons that affect the geometry of the sheets, thus changing their properties.

The hyperfine parameters on all models were calculated giving a/good approach to the experimentally determined by NMR. The equilibrium configuration together with the tetrahedra and octahedral geometry of the $\left(\mathrm{SiO}_{4}\right)$ and $\left(\mathrm{Al} / \mathrm{MgO}_{6}\right)$ units were discussed and related with the corresponding hyperfine parameters.

\section{Acknowledgments}

The authors would like to thank the Argentinian agencies CONICET (grant PIP112 201201 00691) and FONARSEC (grant FSNano-008/2010), the universities Universidad Nacional de La Plata (grant UNLP 1191) and Universidad Nacional del Noroeste de la Prov. de Buenos Aires (grant UNNOBA SIB 2017 Exp. 0176/2017) for the financial support. We also thank the computational centers CSCAA, Aarhus Universitet, Denmark, and Proyecto Acelerado de Cálculo of the SNCAD-MINCyT, Argentina. Finally, to the Instituto de Física La Plata-CONICET, Argentina, for the use of its facilities, and to Dra. R. M. Torres Sanchez for the helping discussions.

\section{References}

(1) Kurniawan T.A.; Chan G.Y.S.; Lo W.H.; Babel S. Physico-chemical treatment techniques for wastewater laden with heavy metals. Chemical Engineering J. 2006, 118, 83-98.

(2) Ismadji S., Soetaredjo, F.. Clay Materials for Environmental Remediation. VIII, p.124; Ed. Ayucitra, Aning, Springer ISBN 978-3-319-16711-4 2015, Chap. 2.

(3) Srinivasan R. Advances in Application of Natural Clay and Its Composites in Removal of Biological, Organic, and Inorganic Contaminants from Drinking Water. Advances in Materials Science and Engineering 2011, 2011, Article ID 872531, p. 17 doi:10.1155/2011/872531. 
(4) Zhu R.; Chen Q.; Zhou Q.; Xi Y.; Zhu J.; He H. Adsorbents based on montmorillonite for contaminant removal from water: a review. Appl. Clay Sci. 2016, 123, 239-258.

(5) Gupta S.S. and Bhattacharyya K.G.. Adsorption of heavy metals on kaolinite and montmorillonite: a review. Phys. Chem. Chem. Phys. 2012, 14, 6698-6723.

(6) Domingo J.L. Cobalt in the Environment and Its Toxicological Implications. Ware G.W. (eds). Reviews of Environmental Contamination and Toxicology (Continuation of Residue Reviews), Springer, New York, NY, 1989; Vol 108.

(7) Abdel-Sabour M.F. Impact of wastewater reuse on cobalt status in Egyptian environment. J. Environ. Sci. 2003, 15, No. 3, 388-395.

(8) Hofmann J.; Leicht R.; Wingender H.J.; Wörner J. Natural Radionuclide Concentrations in Materials Processed in the Chemical Industry and the Related Radiological Impact. European Commission; Nuclear Safety And The Environment Report EUR 19264; 2000.

(9) Cusano G.; Gonzalo M.R.; Farrell F.; Remus R.; Roudier S.; Delgado Sancho L. Best Available Techniques (BAT) Reference Document for the main Non-Ferrous Metals Industries, EUR 28648, 2017, doi:10.2760/8224.

(10) Machender G.; Dhakate R.; Prasanna L.; Govil P.K. Assessment of heavy metal contamination in soils around Balanagar industrial area, Hyderabad, India. Environ. Earth Sci. 2011, 63, 945-953.

(11) Kim J.H. Cobalt and inorganic cobalt compounds. World Health Organization prepared by J.H. Kim, H.J. Gibb, P.D. Howe.2006 ISBN 9789241530699.

(12) Triantafyllou S.; Christodoulo E.; Neou-Syngouna P. Removal of nickel and cobalt from aqueous solutions by Na-activated bentonite. Clays and Clay Miner. 1999, 47, 5, 567-572.

(13) Shou J.; Jiang C.; Wang F.; Qiu M.; Xu Q. Fabrication of $\mathrm{Fe}_{3} \mathrm{O}_{4} / \mathrm{Mg}$ Al-layered double hydroxide magnetic composites for the effective decontamination of $\mathrm{Co}$ (II) from synthetic wastewater. J. Mol. Liq. 2015, 207, 216-223.

(14) Manohar D.M.; Neoline B.F.; Anirudhan T.S. Adsorption performance of Al-pillared bentonite clay for the removal of cobalt(II) from aqueous phase. App. Clay Sci. 2006, 31, 194-206.

(15) Al-Shahrani S.S. Treatment of wastewater contaminated with cobalt using Saudi activated bentonite. Alexandria Eng. J. 2014, 53, 205-211.

(16) Lin S.H.; Juang R.S. Heavy metal removal from water by sorption using surfactantmodified montmorillonite. J. Hazard. Mater. 2002, B92, 315-326. 
(17) Alvarez-Ayuso E.; Garcia Sanchez A. Removal of heavy metals from waste waters by natural and Na-exchanged bentonites. Clays and Clay Miner. 2003, 51, 5, 475-480.

(18) Guo Z.; Li Y.; Zhang S.; Niu H.; Chen Z.; Xu J. Enhanced sorption of radiocobalt from water by $\mathrm{Bi}(\mathrm{III})$ modified montmorillonite: A novel adsorbent. J. Hazard. Mater. 2011, 192, 168-175.

(19) Ma B., Oh S., Shin W.S., Choi S.. Removal of $\mathrm{Co}^{2+}, \mathrm{Sr}^{2+}$ and $\mathrm{Cs}^{+}$from aqueous solution by phosphate-modified montmorillonite (PMM). Desalination, 2011, 276, 336346.

(20) Assaad E.; Azzouz A.; Nistor D.; Ursu A.V.; Sajin T.; Miron D.N.; Monette F.; Niquette P.; Hausler R. Metal removal through synergic coagulation-flocculation using an optimized chitosan-montmorillonite system. App. Clay Sci. 2007, 37, 258-274.

(21) Hashemian S.; Saffari H.; Ragabion S. Adsorption of Cobalt(II) from Aqueous Solutions by $\mathrm{Fe}_{3} \mathrm{O}_{4} /$ Bentonite Nanocomposite. Water Air Soil Pollut. 2015, 226, $2212-$ 2221.

(22) Shawabkeh R.A.; Al-Khashman O.A.; Al-Omari H.S.; Shawabkeh A.F. Cobalt and zinc removal from aqueous solution by chemically treated bentonite. Environmentalist, 2007, 27, 357-363.

(23) Bhattacharyya K.G.; Gupta S.S. Adsorption of a few heavy metals on natural and modified kaolinite and montmorillonite: a review. Adv Colloid Interface Sci. 2008, 140, 114-131.

(24) Matthes W.; Madsen F.T.; Kahr G. Sorption of heavy-metal cations by Al and Zrhydroxy- intercalated and pillared bentonite. Clays and Clay Miner. 1999, 47, 5, 617629.

(25) Kirkpatrick R.J.; Kalinichev A.G.; Bowers G.M.; Özgür Yazaydin A.; Krishnan M.; Saharay M.; Morrow C.P. NMR and computational molecular modeling studies of mineral surfaces and interlayer galleries: a review. Am. Mineral. 2015, 100, 13411354.

(26) Cadars S.; Guégan R.; Garaga M.N.; Bourrat X.; Le Forestier L.; al.. New Insights into the Molecular Structures, Compositions, and Cation Distributions Synthetic and Natural Montmorillonite Clays. Chem. Mater. 2012, 24, 4376-4389.

(27) Woessner D.E. Characterization of clay minerals by ${ }^{27} \mathrm{Al}$ Nuclear Magnetic Resonance spectroscopy. Am. Miner. 1989, 74,203-215.

(28) Ohkubo T.; Kanehashi K.; Saito K.; Ikeda Y. Observation of two 4-Coordinated AI sites in Montmorillonite using High Magnetic Field Strength ${ }^{27}$ AI MQMAS NMR.

Clays and Clay Miner. 2003, 51, No. 5, 513-518. 
(29) Reinholdt M.X.; Brendlé J.; Tuilier M-H.; Kaliaguine S.; Ambroise E. Hydrothermal Synthesis and Characterization of Ni-Al Montmorillonite-Like Phyllosilicates Nanomater. 2013, 3, 48-69; doi:10.3390/nano3010048.

(30) Takahashi T.; Ohkubo T.; Suzuki K.; Ikeda Y. High resolution solid-state NMR studies on dissolution and alteration of Na-montmorillonite under highly alkaline conditions. Micropor. Mesopor. Mater. 2007, 106, 284-297.

(31) Takahashi T.; Kanehashi K.; Saito K. First evidence of multiple octahedral al sites in Na-montmorillonite by ${ }^{27} \mathrm{Al}$ multiple quantum MAS NMR. Clays and Clay Miner. 2008, 56, No. 5, 520-525.

(32) Gates W.P.; Komadel P.; Madejova J.; Bujdak J.; Stucki J.W.; Kirkpatrick R.J. Electronic and structural properties of reduced-charge montmorillonites. App. Clay Sci. 2000, 16, 257-271.

(33) Ohkubo T.; Saito K.; Kanehashi K.; Ikeda Y. A study on hydration behaviors of interlayer cations in montmorillonite by solid state NMR. Sci. Technol. Adv. Mater. 2004, 5, 693-696.

(34) Ejeckam R.B.; Sherriff B.L. A ${ }^{133} \mathrm{Cs},{ }^{29} \mathrm{Si}$, and ${ }^{27} \mathrm{Al}$ MAS NMR spectroscopic study of Cs adsorption by clay minerals: Implications for the disposal of nuclear wastes.

The Canadian Mineralogist, 2005, 43, 1131-1140.

(35) Sullivan D.J.; Shore J.S.; Rice J.A. Assessment of cation binding to clay minerals using solid-state NMR. Clays and Clay Miner. 1998, 46, No. 3, 349-354.

(36) di Leo P. and O'Brien P. Nuclear magnetic resonance (NMR) study of $\mathrm{Cd}^{2+}$ sorption on montmorillonite. Clays and Clay Miner. 1999, 47, No. 6, 761-768.

(37) Fonseca C.G.; de Carvalho G.S.G.; Wypych F.; Diniz R.; Leitão A.A. $\mathrm{Na}^{+}$as a probe to structural investigation of dehydrated smectites using NMR spectra calculated by DFT. Appl. Clay Sci. 2016, 126, 132-140.

(38) Rosso K. M.; Rustad J. R. and Bylaska E. J. The Cs/K Exchange In Muscovite Interlayers: An Ab Initio Treatment. Clays and Clay Miner. 2001, 49, No. 6, 500-513.

(39) Ebina T.; Iwasaki T.; Onodera Y.; Chatterjee A. A comparative study of DFT and XPS with reference to the adsorption of caesium ions in smectites. Comp. Mater. Sci. 1999, 14, 254-260.

(40) He M.C.; Zhao J.; Wang S.X. Adsorption and diffusion of $\mathrm{Pb}(\mathrm{II})$ on the kaolinite (001) surface: A density-functional theory study. Appl. Clay Sci. 2013, 85, 74-79.

(41) Alvim R. S. and Miranda C. R. First principles characterization of silicate sites in clay surfaces. Phys. Chem. Chem.Phys. 2015, 17, 4952. 
(42) Fuller A.J.; Shaw S.; Ward M. B.; Haigh S. J.; J. Mosselmans F.W.; Peacock C. L Stackhouse S.; Dent A. J.; Trivedi D.; Burke I. T. Caesium incorporation and retention in illite interlayers. Appl. Clay Sci. 2015,108, 128-134.

(43) Chatterjee A.; Iwasaki T.; Ebina T.; Miyamoto A. A DFT study on clay-cation-water interaction in montmorillonite and beidellite; Comp. Mater. Sci. 1999, 14, 119-124.

(44) Voora V. K.; Al-Saidi W. A.; Jordan K. D. Density Functional Theory Study of Pyrophyllite and M-Montmorillonites ( $\mathrm{M}=\mathrm{Li}, \mathrm{Na}, \mathrm{K}, \mathrm{Mg}$, and $\mathrm{Ca}$ ): Role of Dispersion Interactions. J. Phys. Chem. A 2011, 115, 9695-9703.

(45) Berghout A.; Tunega D.L; and Zaoui A. Density Functional Theory (DFT) Study Of The Hydration Steps Of $\mathrm{Na}^{+} / \mathrm{Mg}^{2+} / \mathrm{Ca}^{2+} / \mathrm{Sr}^{2+} / \mathrm{Ba}^{2+}$-Exchanged Montmorillonites. Clays and Clay Miner. 2010, 58, No. 2, 174-187.

[46] Pirillo S.; Luna C. R.; Lopez-Corral I.; Juan A.; Avena M. J. Geometrical and Electronic Properties of Hydrated Sodium Montmorillonite and Tetracycline Montmorillonite from DFT Calculations. J. Phys. Chem. C 2015, 119, 16082-16088.

(47) Suter J. L.; Kabalan L.; Khader M.; Coveney P. V. Ab initio molecular dynamics study of the interlayer and micropore structure of aqueous montmorillonite clays. Geochim. Cosmochim. Acta, 2015, 169, 17-29.

(48) Minisini B.; Tsobnang F. Ab initio comparative study of montmorillonite structural models. Appl. Surf. Sci. 2005, 242, 21-28.

(49) Janeba D.; Capkova P.; Schenk H. Molecular simulations of Zn-montmorillonite. Clay Miner. 1998, 33, 197-204.

(50) Wungu T. D. K.; Agusta M. K.; Saputro A. G.; Dipojono H. K.; Kasai H. First principles calculation on the adsorption of water on lithium-montmorillonite (Li-MMT). J. Phys.: Condens. Matter, 2012, 24475506.

(51) Kéri A.; Dähn R.; Krack M.; Churakov S.V. Combined XAFS Spectroscopy and Ab Initio Study on the Characterization of Iron Incorporation by Montmorillonite. Environ. Sci. Technol. 2017, 51, 10585-10594.

(52) Giannozzi R.; Baroni S.; Bonini N.; Calandra M.; Car R.; Cavazzoni C.; Ceresoli D.; Chiarotti G.L.; Cococcióni M.; Dabo I.; Corso A.D.; de Gironcoli S.; Fabris S.; Fratesi G.; Gebauer R.; Gerstmann U.; Gougoussis C.; Kokalj A.; Lazzeri M.; Martin-Samos L.; Marzari N.; Mauri, F.; Mazzarello R.; Paolini S.; Pasquarello A.; Paulatto L.; Sbraccia C.; Scandolo S.; Sclauzero G.; Seitsonen A.P.; Smogunov A.; Umari P.; Wentzcovitch R.M.. QUANTUM ESPRESSO: a modular and open-source software project for quantum simulations of materials. J. Phys. Condens. Matter 2009, 21,395502-395521.

(53) Ordejón P.; Artacho E. and J. M. Soler. Self-consistent order-N density-functional calculations for very large systems. Phys. Rev. B (Rapid Comm.) 1996, 53, R1044110443. Soler J.M.; Artacho E.; Gale J.D.; García A.; Junquera J.; Ordejón P. and 
Sánchez-Portal D.. The SIESTA method for ab initio order-N materials simulation, J. Phys.: Condens. Matt. 2002, 14, 2745-2779.

(54) Sandell E. Colorimetric determination of traces of metals. Interscience Publishers, New York. 1944

(55) Perdew J.P.; Wang Y.. Accurate and simple analytic representation of the electrongas correlation energy. Phys. Rev. B 1992, 45, 13244-13249.

(56) Troullier N. and Martins J.L.. Phys. Rev. B 1991, 43, 1993.

(57) Kleinman L. and Bylander D.M.. Phys. Rev. Lett. 1982, 48, 1425.

(58) Blöchl P.E.. Projector augmented-wave method. Phys. Rev. B 199450 (24), 17953-17979.

(59) Monkhorst H.J. and Pack J.D. Special points for Brillouin-zone integrations. Phys. Rev. B, 1976, 13, 5188-5192.

(60) Pickard C.J. and Mauri F. All-electron magnetic response with pseudopotentials: NMR chemical shifts. Phys. Rev. B 2001, 3, 245101.

(61) Yates J.R.; Pickard C.J. and Mauri, F. Calculation of NMR chemical shifts for extended systems using ultrasoft pseudopotentials. Phys. Rev. B 2007, 76, 024401.

(62) Ferrage E.; Lanson B.; Sakharov B. A.; Drits V. A..Investigation of Smectite Hydration Properties by Modeling of XRay Diffraction Profiles. Part 1. Montmorillonite Hydration Properties. Am. Mineral. 2005, 90, 1358-1374.

(63) Gervais C.; Profeta M.; Babonneau C.; Pickard C.J.; Mauri F. Ab Initio Calculations of NMR Parameters of Highly Coordinated Oxygen Sites in Aluminosilicates. J. Phys. Chem B, 2004, 108, 13249-13253.

(64) Pallister P. J.; Moudrakovski I. L.; Ripmeester J.. A. Phys. Chem. Chem. Phys. 2009, 11, 11487.

(65) Sundholm D., and Olsen, Phys. Rev. Let. 1992, 68927.

(66) Sundholm D., and Olsen, J.. Nucl. Phys. A, 1991, 534, 360. 

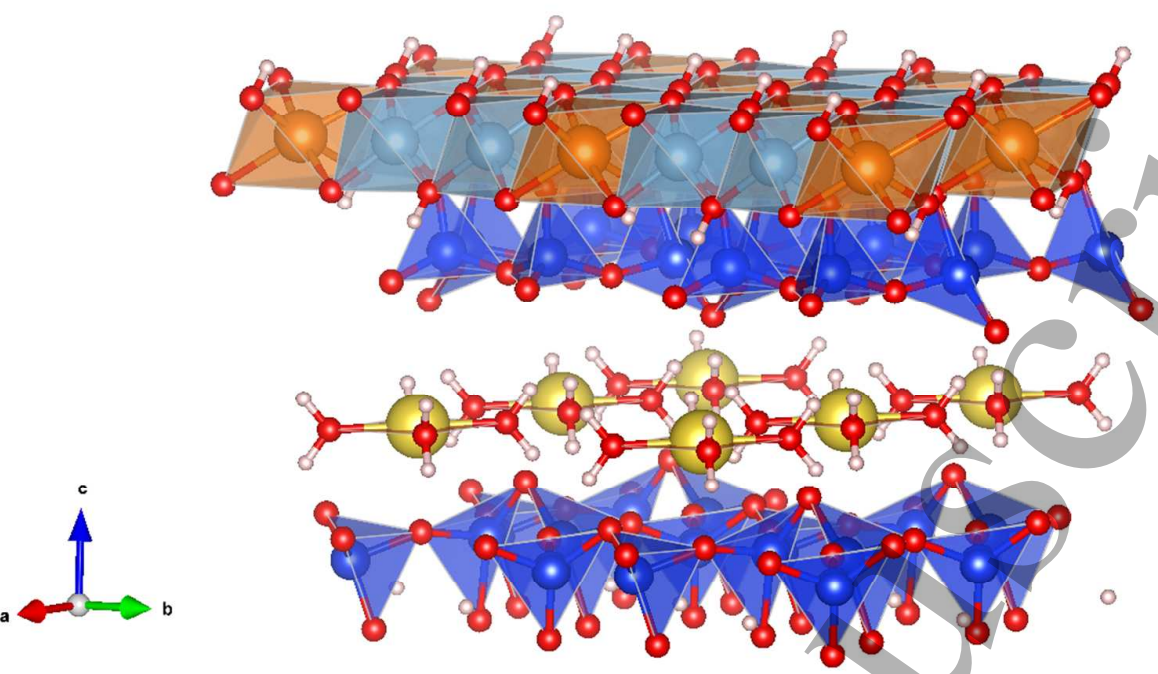

Fig. 1: MMT structure. Si atoms (blue) form tetrahedrons with four bonding $\mathrm{O}$ (red) in $\mathrm{SiO}_{4}$ units. $\mathrm{Mg}$ and $\mathrm{Al}$ atoms (light blue and orange respectively) form octahedrons with the six bonding $\mathrm{O}$ in $(\mathrm{Mg} / \mathrm{Al}) \mathrm{O}_{6}$ units. $\mathrm{H}$ atoms are light-grey. In the interlayer, the $\mathrm{Na}$ atoms (yellow) are surrounded by four $\mathrm{H}_{2} \mathrm{O}$ molecules in this example case.

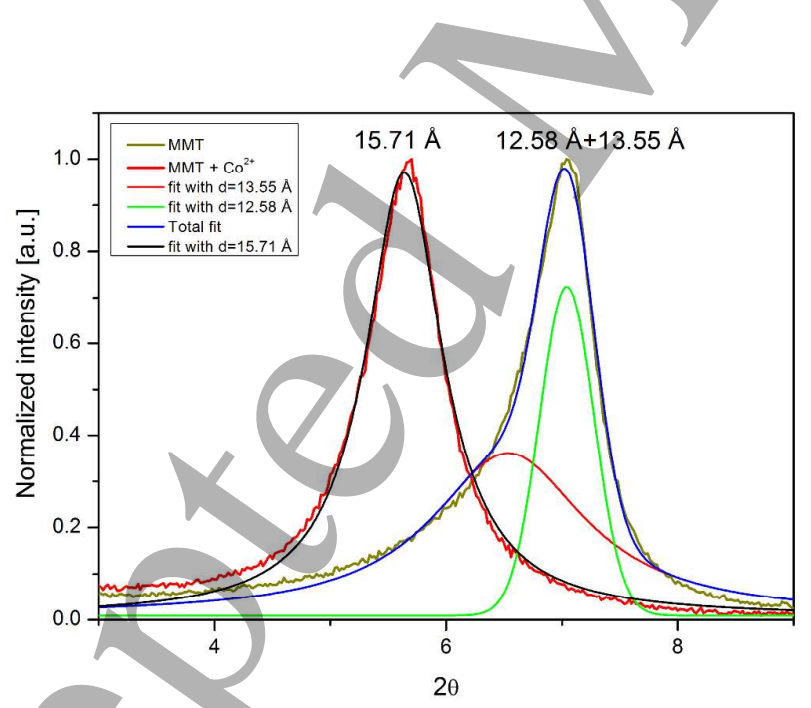

Fig. 2: Partial X-ray diffractions for natural MMT before (dark yellow) and after (red) $\mathrm{Co}^{2+}$ sorption process. The simulated XRD lines obtained from fits with Voight functions are also included 


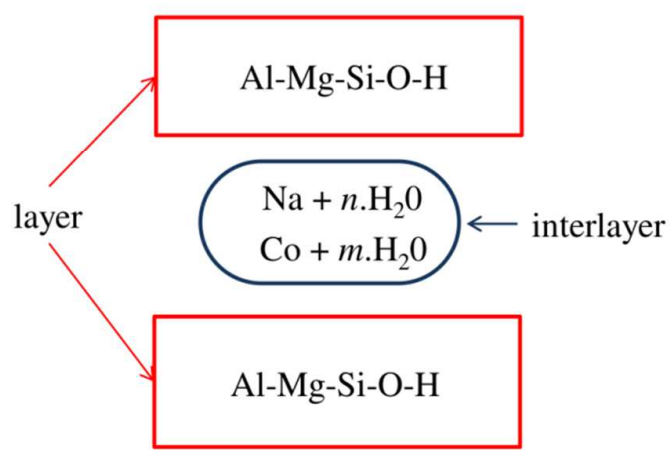

Fig. 3: Schematic division of the unit cell of MMT. The interlayer blocks consist of the $((\mathrm{Al} / \mathrm{Mg}) \mathrm{O} 6)$ and the (SiO4) octahedron/tetrahedron units, while in the interlayer there are the $\mathrm{Na}$ or Co together with their surrounding $\mathrm{H}_{2} \mathrm{O}$.

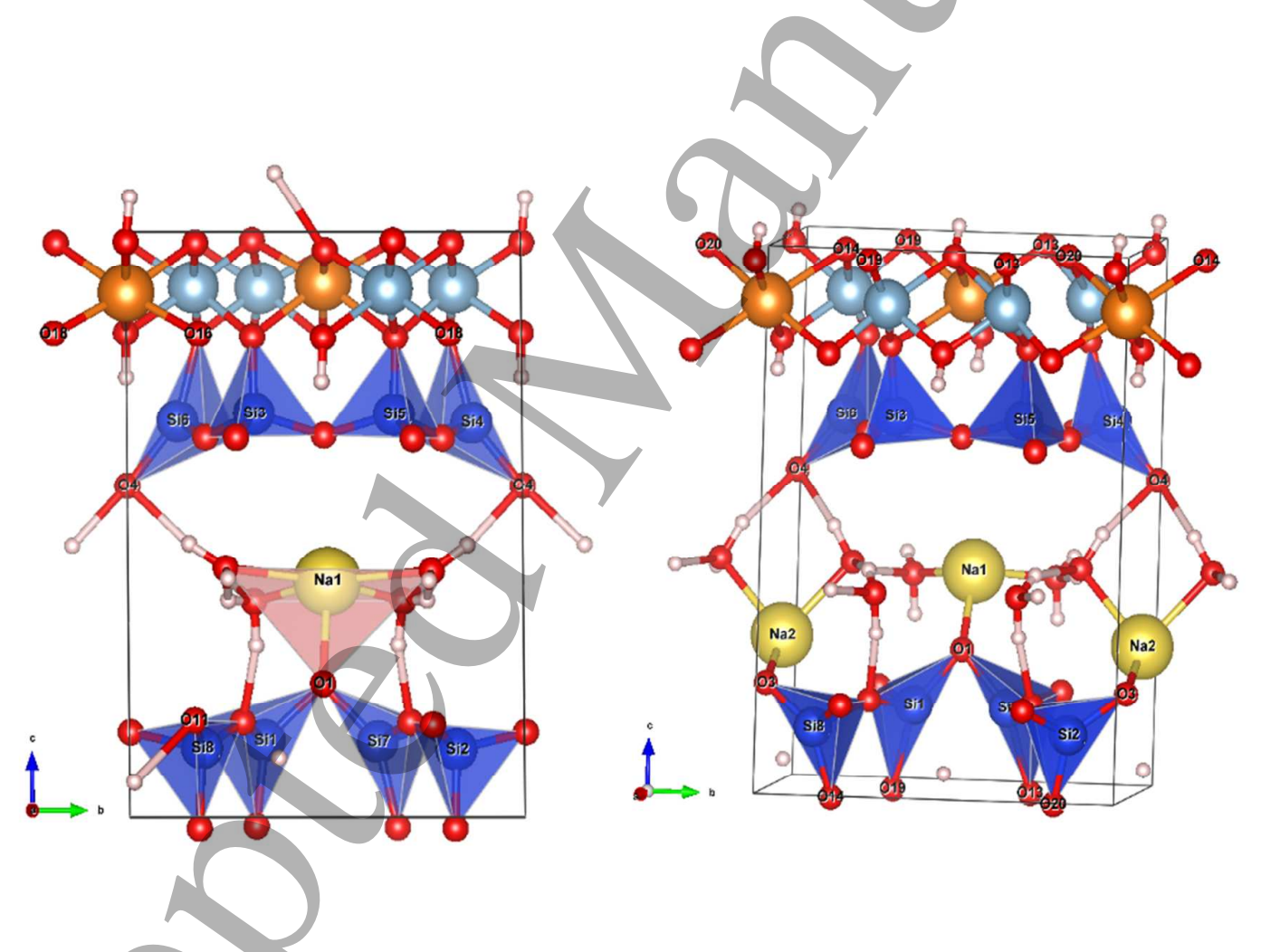

Fig. 4: NaM1 (a) and NaM2 (b) structures after atomic position and cell parameters relaxation. Some $\mathrm{Na}$, Si and $\mathrm{O}$ atoms are numbered in correlation with the text. 

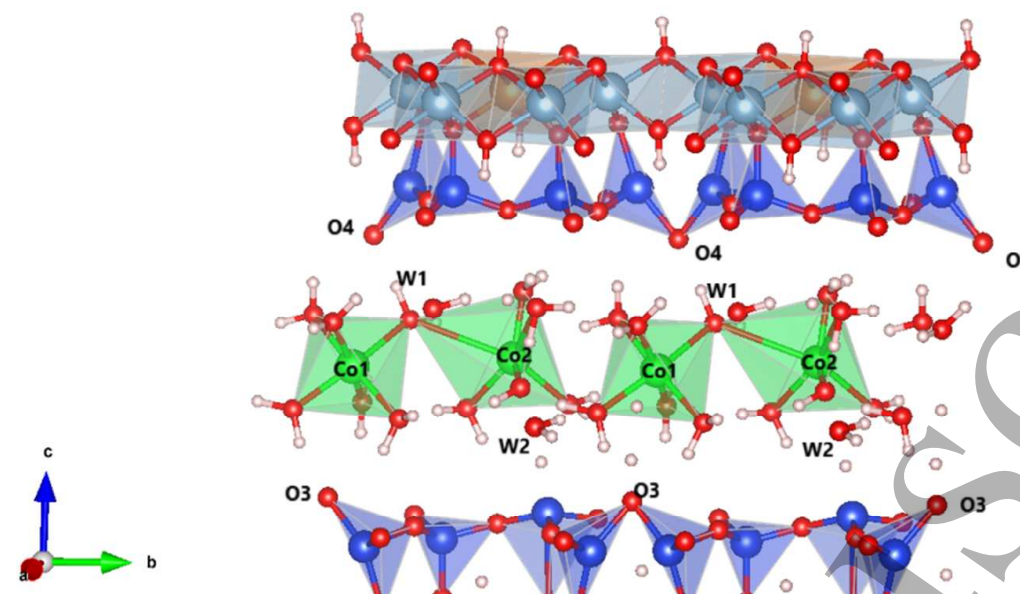

Fig. 5: CoM1 structure after atomic position and cell parameters relaxation. Some Co and $\mathrm{O}$ atoms are numbered in correlation with the text

Table l: Lattice parameters, $d_{001}[\AA]$ and angles $\left[{ }^{\circ}\right]$ obtaíned from the structure relaxation for the different configurations. $\left(^{*}\right)$ data from this work.

\begin{tabular}{|c|c|c|c|c|c|c|c|c|}
\hline & a & b & C & $\alpha$ & $\beta$ & $\mathbf{Y}$ & $\mathrm{d}_{001} \mathrm{Na}-\mathrm{MMT}$ & $\mathrm{d}_{001}$ Co-MMT \\
\hline $\begin{array}{l}\text { Experimental parameters } \\
\text { for Na-MMT from } \\
\text { Ref[46] }\end{array}$ & 5.258 & 8.767 & 12.851 & 90 & 95.3 & 90 & $\begin{array}{c}12.60, \\
12.58 \pm 0.4^{*} \text { and } \\
13.55 \pm 0.07^{*}\end{array}$ & $15.5 \pm 0.6$ \\
\hline NaM1 (1 Na+ $4 \mathrm{H} 2 \mathrm{O})$ & 5.191 & 8.846 & 12.893 & 90.4 & 88.7 & 89.9 & 12.89 & \\
\hline $\mathrm{NaM} 2(2 \mathrm{Na}+4 \mathrm{H} 2 \mathrm{O})$ & 5.256 & 8.767 & 12.795 & 90 & 95.3 & 90 & 12.74 & \\
\hline NaM3 (2 Na + 8 H2O) & 5.210 & 8.857 & 14.191 & 90 & 89.1 & 90.0 & 14.19 & \\
\hline CoM1 (2 Co + $12 \mathrm{H} 2 \mathrm{O})$ & 5.258 & 8.930 & 15.842 & 88.2 & 93.3 & 89.9 & 15.81 & \\
\hline
\end{tabular}

Table Il: Calculated formation and bond energies in $\mathrm{eV}$.

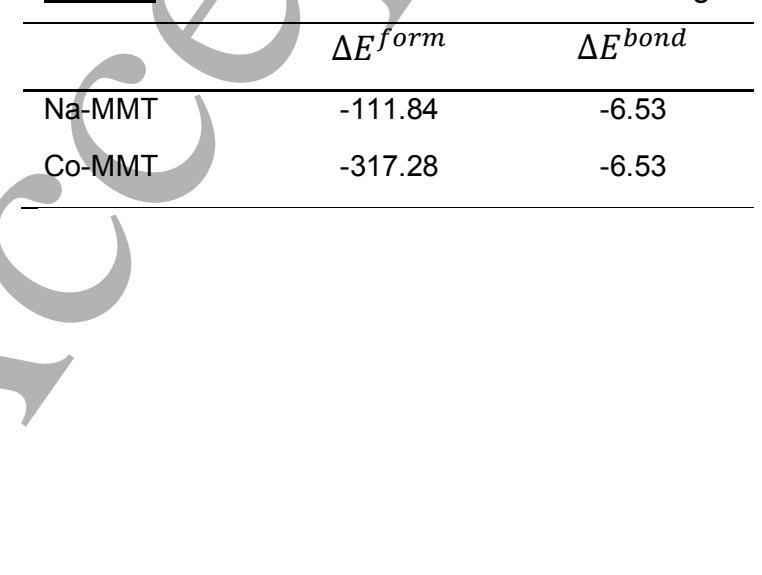


Tabla III: Predicted hyperfine parameters Vzz and $\eta$ and isotropic shielding $\sigma_{\text {sample }}$ for NaM1, NaM2 and CoM1 models. Oxygen atoms are divided in three groups according to their unit positions.

\begin{tabular}{|c|c|c|c|c|c|c|c|c|c|}
\hline & \multicolumn{3}{|c|}{ NaM1 } & \multicolumn{3}{|c|}{ NaM2 } & \multicolumn{3}{|c|}{ CoM1 } \\
\hline atom & $\sigma_{\text {sample }}$ & $\mathbf{V}_{\mathrm{zz}}$ & $\eta$ & $\sigma_{\text {sample }}$ & $\mathbf{V}_{\mathrm{zz}}$ & $n$ & $\sigma_{\text {sample }}$ & $V_{z z}$ & $n$ \\
\hline $\mathrm{Na} 1$ & 569.4 & -0.925 & 0.81 & 562.73 & -1.360 & 0.98 & - & & - \\
\hline $\mathrm{Na} 2$ & - & - & - & 562.73 & -1.032 & 0.47 & - & 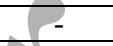 & - \\
\hline Co1 & - & - & - & - & - & - & - & -4.859 & 0.65 \\
\hline $\mathrm{Co} 2$ & - & - & - & - & - & - & - & -10.829 & 0.83 \\
\hline Al1 & 541.66 & -3.572 & 0.19 & 541.08 & -2.504 & 0.44 & 544.01 & 2.300 & 0.39 \\
\hline $\mathrm{Al} 2$ & 544.81 & 0.876 & 0.77 & 538.02 & -2.540 & 0.51 & 541.54 & -1.680 & 0.58 \\
\hline $\mathrm{Al} 3$ & 540.09 & -4.295 & 0.20 & 541.07 & -2.505 & 0.44 & 541.85 & 1.073 & 0.40 \\
\hline Al4 & 542.84 & -0.959 & 0.73 & 538.04 & -2.538 & 0.52 & 544.74 & -1.907 & 0.92 \\
\hline $\operatorname{Mg} 1$ & 546.93 & -1.781 & 0.92 & 551.82 & 1.275 & 0.59 & 551.73 & 1.180 & 0.73 \\
\hline Mg2 & 553.55 & 1.27 & 0.59 & 555.33 & -0.964 & 0.63 & 556.22 & 1.560 & 0.98 \\
\hline Si1 & 464.15 & 3.50 & 0.34 & 428.16 & -3.733 & 0.72 & 426.21 & 2.585 & 0.44 \\
\hline Si2 & 426.28 & 2.80 & 0.59 & 432.81 & -1.577 & 0.64 & 424.46 & -5.758 & 0.30 \\
\hline Si3 & 425.98 & 2.16 & 0.72 & 429.18 & -1.910 & 0.80 & 441.61 & 4.288 & 0.24 \\
\hline Si4 & 413.55 & -4.71 & 0.08 & 430.75 & -3.638 & 0.45 & 424.74 & -4.094 & 0.31 \\
\hline Si5 & 426.64 & 2.10 & 0.66 & 429.18 & -1.897 & 0.80 & 434.85 & 3.326 & 0.39 \\
\hline Si6 & 415.71 & -4.69 & 0.09 & 430.75 & -3.628 & 0.45 & 421.53 & -4.554 & 0.46 \\
\hline Si7 & 409.22 & -2.77 & 0.23 & 428.15 & -3.742 & 0.72 & 436.34 & -1.844 & 0.97 \\
\hline Si8 & 439.24 & -4.32 & 0.30 & 428.15 & -1.571 & 0.64 & 414.26 & -4.347 & 0.41 \\
\hline \multicolumn{10}{|l|}{ Obasal $_{\text {b }}$} \\
\hline O1 & -25.29 & -9.062 & 0.28 & 9.03 & 5.690 & 0.20 & 145.2 & 9.583 & 0.80 \\
\hline $\mathrm{O} 2$ & 194.65 & 9.977 & 0.24 & 177.54 & 8.902 & 0.12 & 190.04 & 10.320 & 0.15 \\
\hline O3 & 169.81 & 9.776 & 0.27 & 1.4 & 5.784 & 0.69 & -87.78 & 4.526 & 0.19 \\
\hline O4 & -76.27 & 5.37 & 0.45 & -44.79 & 5.315 & 0.41 & -87.12 & 4.613 & 0.39 \\
\hline O5 & 162.68 & 9.819 & 0.43 & 121.1 & 10.43 & 0.37 & 152.11 & 10.353 & 0.49 \\
\hline O6 & 134.49 & 10.6 & 0.56 & 121.8 & 9.655 & 0.33 & 151.21 & 9.861 & 0.55 \\
\hline O7 & 164.34 & 9.231 & 0.61 & 182.02 & 9.547 & 0.37 & 167.25 & 9.595 & 0.39 \\
\hline 08 & 160.69 & 9.546 & 0.09 & 163.31 & 9.835 & 0.09 & 160.71 & 10.106 & 0.23 \\
\hline O9 & 162.31 & 9.094 & 0.64 & 181.94 & 9.551 & 0.37 & 169.77 & 10.292 & 0.31 \\
\hline 010 & 162.5 & 9.641 & 0.06 & 163.28 & 9.845 & 0.09 & 157.26 & 9.929 & 0.23 \\
\hline O11 & 85.12 & 6.6 & 0.17 & 121.19 & 10.422 & 0.37 & 163.64 & 9.657 & 0.26 \\
\hline O12 & 165.86 & 9.572 & 0.47 & 121.87 & 9.649 & 0.33 & 140.64 & 10.754 & 0.60 \\
\hline $\mathbf{O}_{\text {apical }}$ & & & & 1 & & & & & \\
\hline 013 & 113.48 & 5.237 & 0.72 & 99.36 & 3.244 & 0.57 & 136.28 & -2.660 & 0.69 \\
\hline O14 & 172.13 & 5.19 & 0.73 & 76.56 & -6.392 & 0.66 & 104.86 & -4.939 & 0.26 \\
\hline 015 & 168.75 & 5.594 & 0.71 & 145.57 & 4.373 & 0.90 & 163.31 & 5.430 & 0.63 \\
\hline 016 & 114.93 & -4.448 & 0.60 & 106.48 & 3.060 & 0.73 & 117.42 & -3.845 & 0.27 \\
\hline 017 & 166.18 & 5.698 & 0.65 & 145.56 & 4.378 & 0.90 & 167.14 & 4.965 & 0.83 \\
\hline 018 & 121.71 & -4.221 & 0.49 & 106.54 & 3.061 & 0.72 & 106.31 & -4.653 & 0.63 \\
\hline O19 & 134.05 & 4.649 & 0.66 & 99.3 & 3.245 & 0.57 & 162.78 & 4.897 & 0.66 \\
\hline O20 & 171.00 & 5.161 & 0.78 & 76.59 & -6.393 & 0.65 & 118.76 & -4.837 & 0.52 \\
\hline \multicolumn{10}{|l|}{$\mathrm{O}_{\mathrm{OH}}$} \\
\hline O21 & 161.9 & -3.872 & 0.91 & 216.81 & 11.988 & 0.10 & 211.54 & 11.036 & 0.32 \\
\hline O22 & 206.26 & 12.316 & 0.17 & 238.5 & 11.609 & 0.19 & 215.62 & 12.073 & 0.25 \\
\hline O23 & 205.13 & 10.757 & 0.36 & 202.35 & 8.868 & 0.34 & 205.38 & 11.064 & 0.40 \\
\hline O24 & 204.54 & 11.209 & 0.29 & 219.69 & 12.210 & 0.24 & 204.51 & 11.450 & 0.41 \\
\hline
\end{tabular}


$\underline{\text { Table IV: }} \sigma_{\text {Ref }}$ and A and B coefficients obtained from literature. ${ }^{a}$ data from Ref[63]. ${ }^{\mathrm{b}}$ data from Ref[64]. ${ }^{\circ}$ data from Ref[37].

\begin{tabular}{|c|c|c|c|}
\hline Isotope & $\sigma_{\text {Ref }}$ & $\mathrm{A}$ & $\mathrm{B}$ \\
\hline${ }^{27} \mathrm{Al}$ & $556.4^{\mathrm{a}}$ & $-0.977^{\mathrm{b}}$ & $541.86^{\mathrm{b}}$ \\
\hline${ }^{29} \mathrm{Si}$ & $337.3^{\mathrm{a}}$ & $-0.920^{\mathrm{b}},-0.825^{\mathrm{c}}$ & $288.45^{\mathrm{b}}, 274.73^{\mathrm{c}}$ \\
\hline${ }^{23} \mathrm{Na}$ & - & $-0.933^{\mathrm{b}},-0.920^{\mathrm{c}}$ & $528^{\mathrm{b}}, 507.733^{\mathrm{c}}$ \\
\hline${ }^{25} \mathrm{Mg}$ & - & $-0.972^{\mathrm{c}}$ & $564.11^{\mathrm{c}}$ \\
\hline
\end{tabular}

Table V: Experimental and calculated chemical shift, $V_{z z}$ and $\eta .{ }^{a}$ using coefficients from Ref[64]. ${ }^{b}$ using coefficients from Ref[37]. ${ }^{c}$ using coefficients from Ref[63]. ${ }^{d}$ data from Ref[33]. ${ }^{e}$ data from Ref[30]. ${ }^{f}$ data from Ref[26]. ${ }^{9}$ data from Ref[65]. ${ }^{\mathrm{h}}$ data from Ref[66].

\begin{tabular}{|c|c|c|c|c|c|c|c|c|c|c|}
\hline & & \multicolumn{3}{|c|}{ exp } & \multicolumn{2}{|c|}{ Na-M1 } & & \multicolumn{3}{|c|}{ Na-M2 } \\
\hline Probe & $\mathbf{Q}[\mathrm{mb}]$ & $\delta_{\text {chem }}$ & $\mathrm{V}_{\mathrm{zz}}$ & $\eta$ & $\delta_{\text {chem }}$ & $V$ & $\eta$ & $\delta_{\text {chem }}$ & $V_{z z}$ & $\eta$ \\
\hline${ }^{27} \mathrm{Al}$ & $140.2^{\mathrm{g}}$ & $6.9^{e}$ & $2.7-3.12$ & & $\begin{array}{l}11.98^{\mathrm{a}} \\
14.05^{\mathrm{c}}\end{array}$ & 2.43 & 0.47 & $\begin{array}{l}14.72^{\mathrm{a}}, \\
16.85^{\mathrm{c}}\end{array}$ & 2.52 & 0.48 \\
\hline${ }^{29} \mathrm{Si}$ & & $\begin{array}{l}-93.7 \text { natural } \mathrm{MMT}^{f} \\
\text {-88.6 synthetic } \mathrm{MMT}^{f}\end{array}$ & & & $\begin{array}{l}-104.9^{\mathrm{a}} \\
-78.2^{\mathrm{b}} \\
-90.3^{\mathrm{c}}\end{array}$ & & & $\begin{array}{l}-106.8^{\mathrm{a}}- \\
79.93^{\mathrm{b}} \\
-92.34^{\mathrm{c}}\end{array}$ & & \\
\hline${ }^{23} \mathrm{Na}$ & $109^{g}$ & $-6^{d}$ & $1.44^{\mathrm{d}}$ & & $\begin{array}{l}-3.25^{a} \\
-16.2^{b}\end{array}$ & 0.93 & & $\begin{array}{l}-2.97^{\mathrm{a}} \\
-10.0^{\mathrm{b}}\end{array}$ & 1.20 & \\
\hline${ }^{25} \mathrm{Mg}$ & $199.4^{h}$ & $16^{f}$ & 0.7 & 0.61 & $29.3^{b}$ & 1.52 & 0.76 & $26.09^{b}$ & 1.12 & 0.61 \\
\hline
\end{tabular}

